\title{
History, Types and Regeneration of Gasholders
}

\author{
Haiying $\mathrm{Li}^{1, *}$ \\ ${ }^{1}$ School of Architecture and Art, North China University of Technology, Beijing, China \\ "Corresponding author. Email: 228377941@qq.com

\begin{abstract}
With tall images, gasholders not only have witnessed the history and civilization of industrial productions but also have become local landscape landmarks. This paper reviews the historical generations of gasholders and summarizes the appearance evolutions and characteristics. Starting with the shape, structure, and type of the gas storage tank, this paper analyzes the typical examples of the transformation and reuse of the gasholders and puts forward the ways and strategies of the transformation and regeneration of the industrial gasholders.
\end{abstract}

Keywords: gasholder, industry heritage, regeneration strategies, transformation ways

\section{INTRODUCTION}

Due to their tall image, the gasholders or gasometers often become local landscape landmarks. At the same time, in the public consciousness, they are also inseparable from local life, witnessing the history and civilization of industrial development. In the past 10 years or more, the transformation and reuse of gasholders have become the mainstream in Europe. While using these abandoned structures, people can also experience the history of cities through these structures. Many of them have become the main drivers of industrial heritage tourism and urban renewal. As we study how to retrofit and reuse these gas storage tanks, we need to understand their history, types, and evolution.

\section{THE ORIGIN OF GASHOLDERS}

\section{A. Etymological concept of "gasholder" and "gasmeter"}

European people often refer to gasholder as a gasometer, but distinguish the etymological concept of "gasholder" from "gasometer". The suffix "-meter" stands for measuring instrument, while "gasometer" is an instrument for measuring the amount of gas. "Gasholder" is used to store manufactured gas, which is more suitable for its functions and expresses its meaning more accurately.

\section{B. The origin of function}

Before the middle of the 20th century, gas was produced by heating coal without air, a process known as coal gasification. Gas was first used for city lighting, and was piped through wooden or metal pipes from distillers to lamps. In 1807, the first public piped gas supply system was installed along London's Pall Mall with 13 gas lamps. Later, it was widely used for home lighting, heating and cooking. The public gas supply system gradually moved eastward from Britain to the whole of Europe. In the face of a large amount of gas demand, the advent of gasholder plays a buffer role, providing storage and measurement of gas, eliminating the need for continuous production of gas. During dinner time, for example, when the demand for gas increases, the gas storage tank will drop, providing a boost service to the area pipeline.

\section{Types of gasholders}

The first gas tanks used for public lighting had a small capacity because they were mainly used for the main squares and streets of the city. There are two basic types of gas storage tank: water-sealed and rigid anhydrous (see "Fig. 1"). Water-sealed type includes small single-lift gasholder, frame-oriented multi-lift telescopic gasholder and spiral telescopic gasholder. Piston type gas holder with the highest volume belongs to anhydrous gasholder [1]. 


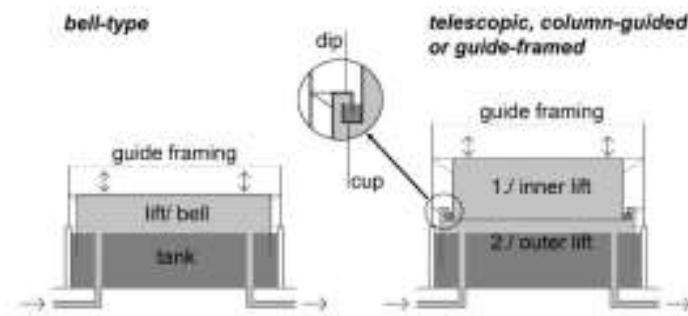

telescopic, spirat-guided
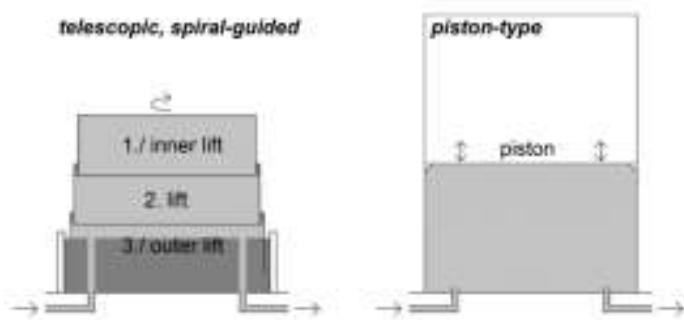

Fig. 1. Main development types of gasholders. ${ }^{1}$

\section{Water-sealed gas storage tank}

The water-sealed gas holder consists of two parts: a deep-water tank for sealing and a closed container that rises as the volume of the gas increases. Water tanks are usually constructed of wood, brick, cast iron, steel, or concrete. There are three types of water tank locations: above ground, semi-underground, and fully underground. Generally, water tanks on the ground are usually equipped with a protective wall above the ground.

1) Single-lift gas holder (also known as bell type)

The single-lift tank consists of a water tank, a sealed container on the water tank and a guide frame, as shown in "Fig. 2". The guide frame ensures the up-anddown movement of the lift. Earlier guide structures used brick columns, then cast iron columns, often decorated with flame-style pillars for aesthetics.

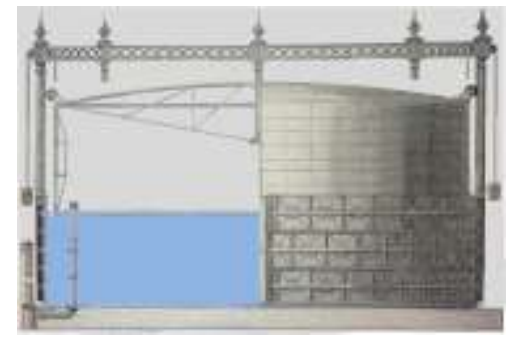

Fig. 2. Section and appearance of bell type. ${ }^{2}$

1 Barbara Berger. The Gasholder-Shaped by Its Function. 5th International Congress on Construction History Proceedings. Vol. 1. Chicago, 2015, pp. 203-210

2 Russell Thomas. Regeneration \& redevelopment stories from around the world. https://www.researchgate.net/publication/268447890
2) Telescopic gasholder

a) Telescope, column or frame guided gasholder

As demand for natural gas increased in the second half of the 19th century, larger capacity tanks were needed. The telescopic lift system upgrades single-lift tanks to two-lift or multi-lift telescopic tanks, even with some large tanks capable of up to 7 lifts. The most complex feature of this structure is the airtight connection between the upper head and the lower head. With the increase of the height, the column guide structure is replaced by lattice beam and column ("Fig. 3").

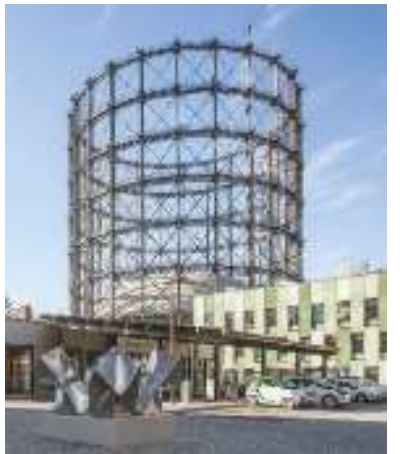

Fig. 3. The telescope gasholder - Frame guided gasholder.

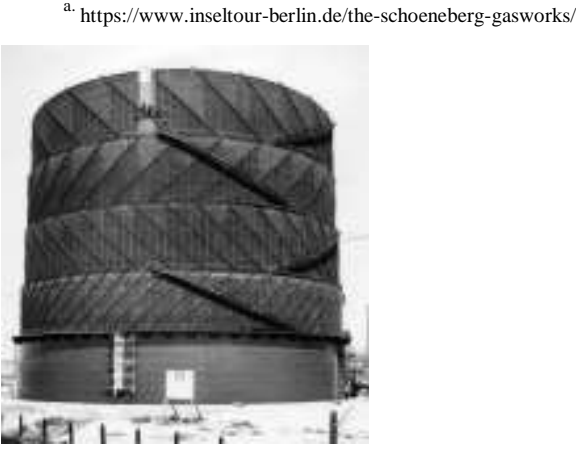

Fig. 4. The telescope gasholder -4 lifts, spiral guided. ${ }^{3}$

\section{b) Telescope, spiral-guided gasholder}

At the end of the 19th century, spiral-guided gas tanks changed the appearance of gas tanks, eliminating the need for an external guided frame, allowing rapid expansion of storage capacity and low cost ("Fig. 5"). This gas holder is also suitable for water-sealing systems, where the elevator spirals up and down, almost disappearing underground when the tank is empty [2].

Barbara Berger. The Gasholder-Shaped by Its Function. 5th International Congress on Construction History Proceedings. Vol. 1. Chicago, 2015, pp. 203-210 


\section{E. Rigid anhydrous gas tank}

At the end of the 19th century, water-sealed gas tanks were built on such a scale that they reached the limits of construction: the huge diameter and volume of the tanks exceeded the possible ground pressure, and the tanks were always heated in winter. To avoid these problems, at the beginning of the 20th century, a new technology was developed: rigid, waterless piston gas storage tanks. The gas holder consists of a closed cylindrical structure and a piston moving up and down according to the actual gas content. The piston is hidden in the cylinder, which is as invisible as the lift, and a sealing system is adopted along the piston edge [3]. Piston type gas storage tank does not use water, oil or other liquid seal, can store the water soluble gas, but also can store the gas containing fine solids such as dust, good seismic performance. "Fig. 5" shows the Southall Man rigid waterless piston gas storage tank located near Heathrow Airport, $95 \mathrm{~m}$ high, $60 \mathrm{~m}$ in diameter, much larger than the water-sealed gas tank.

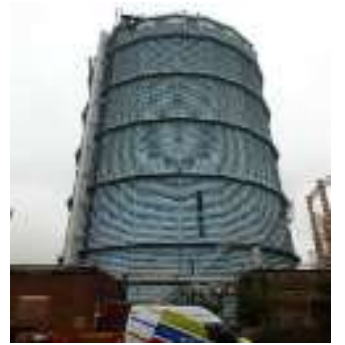

Fig. 5. A piston gasholder.

https://andun.co.uk/case_studies/southall-man-gas-holder-demolition/

\section{THE VALUE OF GASHOLDERS}

\section{A. Historic value}

Although gas cabinet no longer bears its production function, they are the witness of a city history, the expression of city history, and the memory of industrial production and life at that time. The remolding of gas tank's history and social value is of far-reaching significance to the protection and renewal of old industrial areas and even historic urban districts.

\section{B. Landscape value}

Due to its huge volume, the gas tank naturally becomes a landmark of an industrial area and even the whole area, which has unique visual marking and landscape value. Over the years, people have been used to orientate with it, creating a unique place characteristic in psychology.

\section{Structure value}

With the development of cast iron structure technology, steel structure processing technology and mechanical technology, gas tank has become larger and larger. The structure reflects the development of history and shows the track of human civilization.

\section{ANALYSIS OF SUCCESSFUL TRANSFORMATION}

\section{A. Gasholders of King's Cross, London, UK}

It is the largest gas plant in London, close to the king's cross station and St Pancreas station, and easily accessible. The gas storage unit was originally built in the 1850 s and expanded in 1883 until it was officially decommissioned in 2000. Only four gas storage tanks were retained and modified (see "Fig. 6").

The four tanks are all frame-guided three-lift telescopic tanks. Disassemble the original cast iron structures, and reinstall them on site after technological treatment. No. 8 gas tank is the largest storage tank and has been converted into an outdoor garden. With an inner diameter of over $35 \mathrm{~m}$, two layers of cast iron riveted lattice beams, up to $25 \mathrm{~m}$. In the center is a circular lawn, which rises above the ground to symbolize the berm of the water tank. The lawn is surrounded by a stainless-steel pavilion with a ceiling and seats ("Fig. 7"). The simple modern stainless steel and retro cast iron column feet form a "beautiful juxtaposition of old and new".

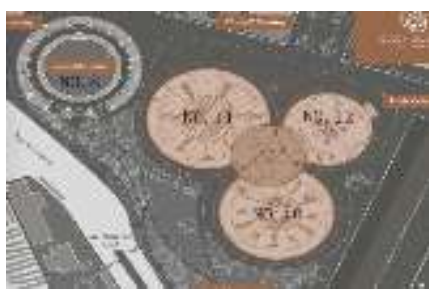

Fig. 6. Gasholders of King's Cross - Master plan.

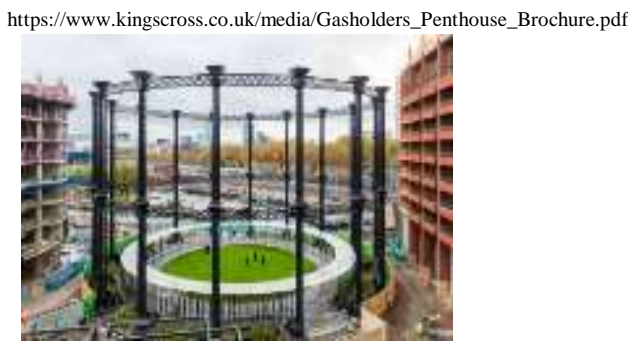

Fig. 7. Gasholders of King's Cross - Gasholder park. 


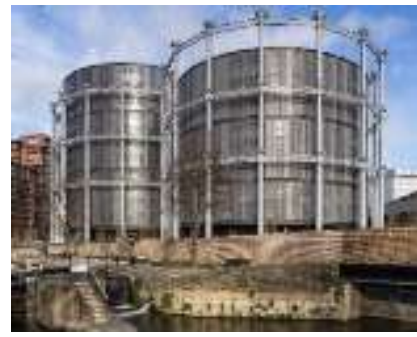

Fig. 8. Gasholders of King's Cross - Apartments, No.10-12 gasholders.

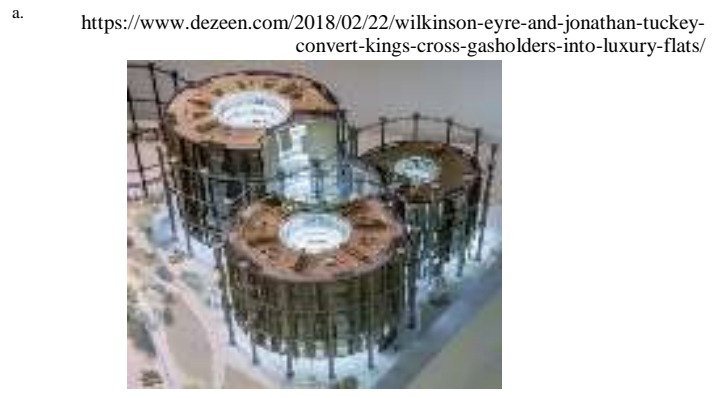

Fig. 9. Gasholders of King's Cross - Scattered roof garden of apartments.

a. https://thespaces.com/gasholder-conversions-a-glimpse-inside-the-show-flat-
for-the-kings-cross-triplets/4/

Gas storage units 10, 11 and 12 were converted into a living group, accommodating 145 luxury apartments, including 9 penthouses, private gym and spa, business lounge and entertainment facilities ("Fig. 8"). The existing pool is reuse to expand the underground parking space. The three buildings have different roof heights, forming a patchwork roof garden that can be seen from one another ("Fig. 9"). At the same time, it also refers to the different internal gas volume of different gas tanks. The original structure is exposed and the facade is located inside the frame. The skin is made of metallic stainless-steel hollow panels and movable vertical shading perfectly reflecting the structural and industrial aesthetic.

\section{B. Gasometer, Vienna, Autstria}

Earlier, people thought that the gas tank might explode outside, so they built a cylinder of heavy masonry outside the tank. The advantage of this is that the guiding frame of the gas tank can be installed on the inside of the building to protect the tank from the effects of the sun, rain and extreme weather on the machinery, especially the water seal. However, the gas may leak from the gas cabinet into the room, which may cause an explosion [4].

In 1981, as an outstanding example of industrial architecture, Vienna's gas cabinet houses, built between 1896 and 1899 as four brick-clad gas cabinet houses ("Fig. 10"), were listed as protected monuments. Each is 60 meters in diameter and 70 meters in height. Inside is a cylindrical retractable water seal gas tank with a volume of about 90,000 cubic meters

The renovation was completed in 1999-2001 ("Fig. 11").The original internal gas tank was removed, leaving only the red brick skin and part of the roof structure ("Fig. 12").Four gas tank shop is divided into several regions, respectively, used to live in the apartment (top) ("Fig. 13"), the working office (middle), learning, entertainment and shopping (at the bottom of the shopping center), also includes a accommodate more than 2000 people in the concert hall, the parts in a bridge link channel is four layers, can become a housebound office live entertainment complex [5].

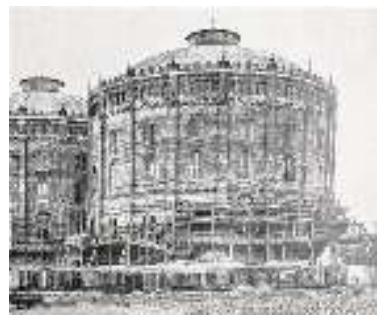

Fig. 10. Gasometer, Vienna - Early photo of Vienna gasometer.

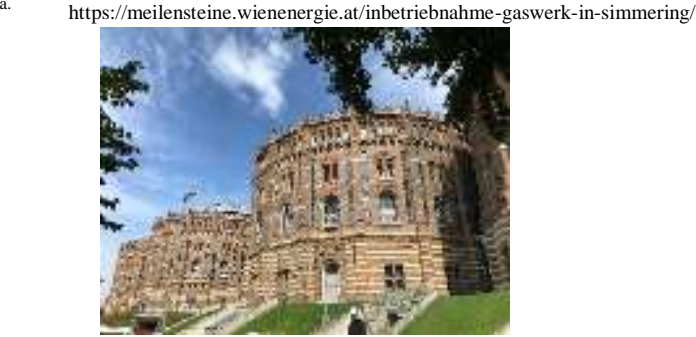

Fig. 11. Gasometer, Vienna — the photo after rebuild

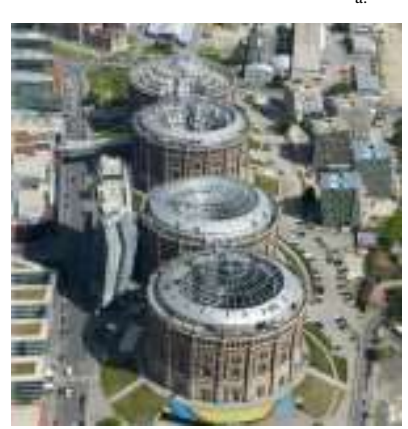

Taken by the author

Fig. 12. Gasometer, Vienna - Bird view photo.

https://www.greatbigcanvas.com/view/the-gasometers-vienna-austria-aerialphotograph,2061488/ 


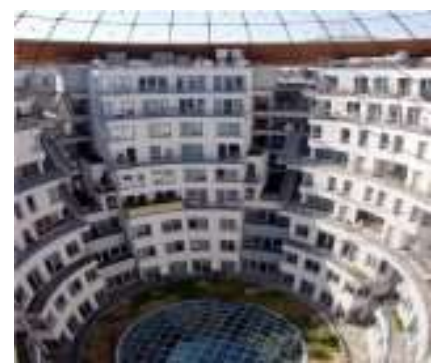

Fig. 13. Gasometer, Vienna - Apartment inner courtyard.

https://twistedsifter.com/2009/10/gasometers-of-vienna

\section{TauchRevier Gasometer, Duisberg, Germany}

TauchRevier Gasometer is a frame-guided multi-lift water seal gas holder built in the 1920 s ("Fig. 14"). It has a diameter of 45 meters and a depth of 13 meters. Transformed into the largest indoor diving and training center in Europe, the gas tank can contain 21 million liters of fresh water, with visibility up to 25 meters and water temperatures varying with the seasons (around $7^{\circ} \mathrm{C}$ in winter and $26^{\circ} \mathrm{C}$ in summer). Features include equipment rental rooms, changing rooms, showers, and shops ("Fig. 15, Fig. 16 and Fig. 17").

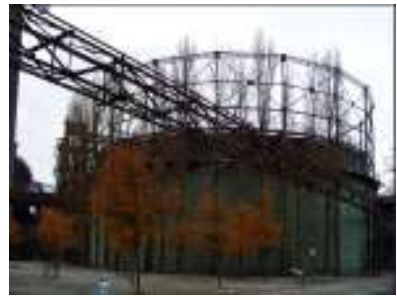

Fig. 14. TauchRevier Gasometer - Outer appearance.

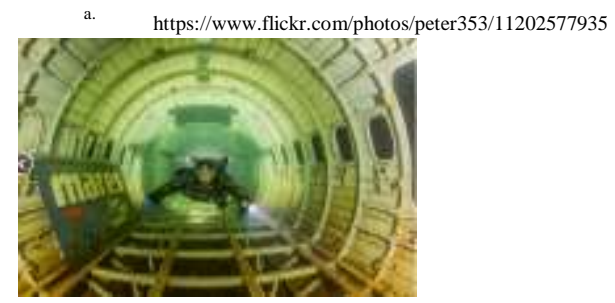

Fig. 15. TauchRevier Gasometer - Internal diving passage.

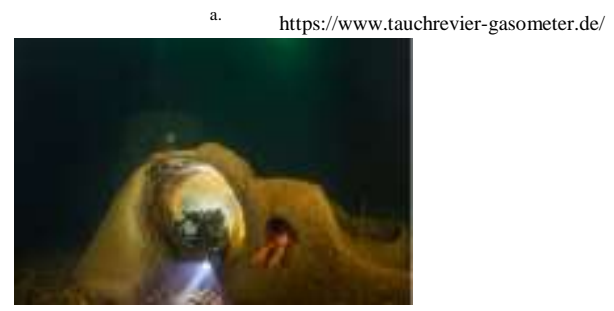

Fig. 16. TauchRevier Gasometer - Underwater landscape.

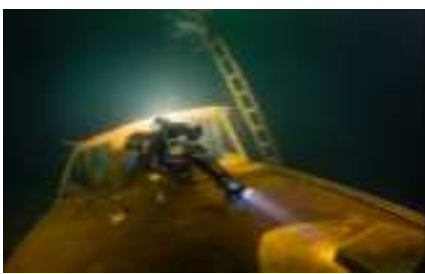

Fig. 17. TauchRevier Gasometer - Underwater landscape.

https://www.tauchrevier-gasometer.de/

\section{Gasometer Oberhausen, Germany}

Oberhausen is a city near the Ruhr River. Oberhausen gas tank ("Fig. 18") was built in 1927 and was bombed during World War II. Twenty years later, it was rebuilt as a waterless piston gas tank, 117 meters high and 69 meters in diameter, perched on a 24-sided polygonal base with a metal frame and a steel shell, capable of holding 347,000 cubic meters of volume, and was in use until 1988, weighing 600 tons and rising to 97 meters [6].

After the renovation ("Fig. 19"), the piston is anchored at a height of 4.5 meters, creating a 3,000square-meter hall that serves as a reception and exhibition space on the ground floor. The remaining cylindrical space above the hall covers an area of 7,000 square meters and is 90 meters high. There have been many exhibitions since, including installations by Kristof, Jenny Claude and Bill Viola. With the modern projection, one can lie on the soft mat of the ground step and watch the three-dimensional mapping at the top ("Fig. 20"). The roof is a wooden structure shaped like the spokes of a car ("Fig. 21"), forming an impressively tall exhibition space known as the "cathedral of industry". The exhibition gives full play to the great space role and becomes the highlight of the new exhibition space.

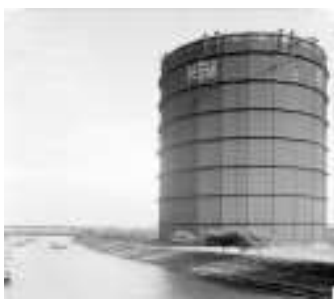

Fig. 18. Gasometer Oberhausen — before modification.

https://www.gasometer.de/en/the-gasometer/technology 


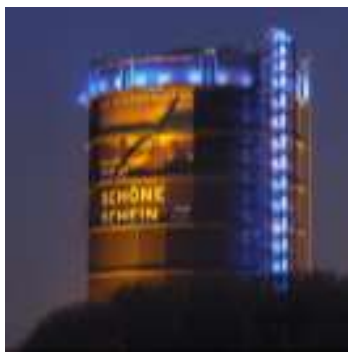

Fig. 19. Gasometer Oberhausen - after modification.

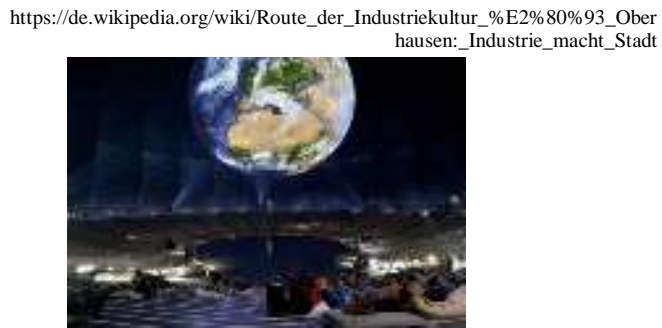

Fig. 20. Gasometer Oberhausen - Exhibition place.

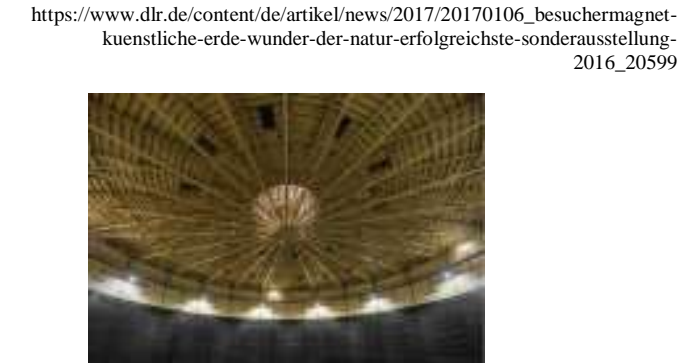

Fig. 21. Gasometer Oberhausen - the roof structure.

https://blog.michaelrasche.com/2016/01/gasometer-oberhausen/

\section{THE TRANSFORMATION STRATEGY OF GASHOLDERS}

\section{A. Functional space is reshaped to focus on human experience}

Due to the huge scale of the gas storage tank, there is no column wall and other partitions inside, and there is no height limit, so the flexibility of the space transformation is very high. Spaces can often be converted into residential, office, commercial, entertainment and exhibition buildings. Some sports and entertainment features are also well suited, such as scuba diving, which takes advantage of its good air tightness, high-altitude rock climbing and rapid descent. Make the most of its height, exterior or frame structure, and all Spaces focus on human participation and experience.

\section{B. Highlighting the original structure and skin aesthetics}

With the increase of volume and lift, the guiding frame type is higher and higher, which is supported by simple beam and column, gradually becomes lattice beam and column type, and also increases the diagonal brace to resist lateral force. The British cast iron craft level is very high, riveted beam-column structure, the pillar head and the column foot has the beautiful thread foot and the decoration. Therefore, in the later transformation, the water-sealed gas tank with a guiding frame will almost make the structure exposed, reflecting the original structural logic and structural beauty. But anhydrous gas holder and spiral type water seal gas holder will retain its metal casing commonly, reflecting the beauty of industry.

For the current preservation of good quality gas tank house, most of them are made of red brick or stone masonry. They tend to be proportionally balanced, with fine details on eaves, bases, door and window covers, pilasters and other positions. Therefore, the original color and material of the outer skin will be used to set up the internal support structure and transform the internal space.

\section{Old and new juxtaposition and continuation of context}

Effort should be paid to enhance the sense of belonging by extracting local materials, textures, colors and components, combining exhibition hall and museum to reproduce some dynamic production process and preserving the site structures. By means of spatial metaphor and symbol, the dialogue between people and space is endowed; The comparison and juxtaposition of the old and new materials makes history more prominent and arouses the resonance of people's thinking and thinking.

\section{Creating a landmark night view}

The tall scale of the gas storage tank is often used as a landmark to carry the life and emotions of the local people in the local history. Through floodlights, clearance lights and key lighting at night, more attention is paid to the creation of landscape landmarks at night.

\section{CONCLUSION}

According to its type, shape and structural characteristics, the high image gas holder can pay attention to the user's feeling and experience by implanting new functions and reshaping the space. Highlight structural logic and industrial aesthetics. By extracting local materials, textures and colors and using spatial metaphors and symbols, the context can be continued and the new and the old can be juxtaposed. 
By means of creating night scenery and highlighting landscape landmarks, the gas tank of industrial heritage can be utilized, regenerated and continued according to local conditions.

\section{References}

[1] Barbara Berger. The Gasholder-Shaped by Its Function. 5th International Congress on Construction History Proceedings. Vol. 1.Chicago, 2015, pp. 203-210

[2] Russell Thomas. The History of the Gasholder. IGEM Gasholder Conference, 2014.

[3] Russell Thomas. Regeneration \& redevelopment stories from around the world [C]. IGEM Gasholder Conference, 2014.

[4] Russell Thomas. Gasholder and their tanks. www.academia.edu, 2015.

[5] Cristina Tartás Ruiz, Zollverein's gasometers: a remarkable restoration.

[6] Luigi Fiorino, Raffaele Landolfo, Federico Massimo Mazzolani. The refurbishment of gasometers as a relevant witness of industrial archeology [J]. Engineering Structures (84), 2015. 